\title{
Prevalence and underdiagnosis of chronic obstructive pulmonary disease among patients at risk in primary care
}

\author{
Kylie Hill BSc(PT) PhD, Roger S. Goldstein MB ChB, Gordon H. Guyatt MD MSc, Maria Blouin RRT, \\ Wan C. Tan MBBS MD, Lori L. Davis BSc, Diane M. Heels-Ansdell MSc, Marko Erak, \\ Pauline J. Bragaglia BMedSc MD, Itamar E. Tamari MD, Richard Hodder MSc MD, \\ Matthew B. Stanbrook MD PhD
}

Previously published at www.cmaj.ca

\section{ABSTRACT}

Background: People with known risk factors for chronic obstructive pulmonary disease (COPD) are important targets for screening and early intervention. We sought to measure the prevalence of COPD among such individuals visiting a primary care practitioner for any reason. We also evaluated the accuracy of prior diagnosis or nondiagnosis of COPD and identified associated clinical characteristics.

Methods: We recruited patients from three primary care sites who were 40 years or older and had a smoking history of at least 20 pack-years. Participants were asked about respiratory symptoms and underwent postbronchodilator spirometry. COPD was defined as a ratio of forced expiratory volume in the first second of expiration to forced vital capacity (FEV $/$ FVC) of less than 0.7 and an $\mathrm{FEV}_{1}$ of less than $80 \%$ predicted.

Results: Of the 1459 patients who met the study criteria, $1003(68.7 \%)$ completed spirometry testing. Of these, 208 were found to have COPD, for a prevalence of $20.7 \%$ (95\% confidence interval $18.3 \%-23.4 \%)$. Of the 205 participants with COPD who completed the interview about respiratory symptoms before spirometry, only $67(32.7 \%)$ were aware of their diagnosis before the study. Compared with patients in whom COPD had been correctly diagnosed before the study, those in whom COPD had been overdiagnosed or undiagnosed were similar in terms of age, sex, current smoking status and number of visits to a primary care practitioner because of a respiratory problem.

Interpretation: Among adult patients visiting a primary care practitioner, as many as one in five with known risk factors met spirometric criteria for COPD. Underdiagnosis of COPD was frequent, which suggests a need for greater screening of at-risk individuals. Knowledge of the prevalence of COPD will help plan strategies for disease management.

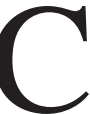
hronic obstructive pulmonary disease (COPD) is a common and costly condition worldwide. ${ }^{1,2} \mathrm{~A}$ recent global population-based study estimated the prevalence of the disease to be about $10 \%$ among people 40 years of age and older. ${ }^{3}$ People with known risk factors for COPD, such as increased age and a history of smoking, are likely to have a substanially higher prevalence ${ }^{4-6}$ and to have progressive manifestations of COPD if they continue to smoke. ${ }^{7}$ They are thus appropriate targets for intervention early in the course of their disease.

People with early or undiagnosed COPD are most likely to encounter the health care system in the primary care setting. Consequently, accurate knowledge of the prevalence of COPD in this setting is critical to planning and implementing strategies for the detection and management of the disease. However, valid estimates are lacking of the prevalence of COPD among at-risk individuals in primary care practices. Access by family doctors to spirometric data confirming irreversible airway obstruction has been shown to influence patient management ${ }^{8}$ and to enable implementation of a targeted self-management plan that may include smoking cessation, pharmacotherapy and increased exercise. ${ }^{9-11}$

We sought to measure the prevalence of spirometrically confirmed COPD in an at-risk population of adults aged 40 years or more with a smoking history of at least 20 pack-years who visited a primary care practitioner (physician or nurse practitioner) for any reason and to describe their characteristics. We also evaluated the accuracy of prior diagnosis or nondiagnosis of COPD and to identify associated clinical characteristics.

\section{Methods}

The research ethics committees of the University of Toronto and the Sault Saint Marie Group Health Centre approved this study.

From the West Park Healthcare Centre (Hill, Goldstein, Blouin, Davis, Erak), Toronto, Ont.; the Departments of Physical Therapy and Medicine (Hill, Goldstein, Stanbrook), University of Toronto, Toronto, Ont.; the Departments of Clinical Epidemiology and Biostatistics and of Medicine (Guyatt, HeelsAnsdell), McMaster University, Hamilton, Ont.; the James Hogg iCAPTURE Centre for Cardiovascular and Pulmonary Research (Tan), St. Paul's Hospital and University of British Columbia, Vancouver, BC; the Algoma District Medical Group (Bragaglia), Group Health Centre, Sault Saint Marie, Ont.; Faculty of Medicine, Northern Ontario School of Medicine (Bragaglia), Laurentian University, Sudbury, Ont., and Lakehead University, Thunder Bay, Ont.; Stonegate Community Health Centre (Tamari), Toronto, Ont.; the Divisions of Pulmonary and Critical Care Medicine (Hodder), University of Ottawa, Ottawa, Ont.; and the University Health Network (Stanbrook), Toronto, Ont.

CMAJ 2010. DOI:10.1503/cmaj.091784 


\section{Recruitment and enrolment}

Participants were recruited from April 2006 to February 2007 from three primary care sites in the province of Ontario representing rural, suburban and urban populations. These sites had previously participated in a provincial study of asthma. Doctors at each site were family physicians without specialization in respiratory medicine. Identification of participants varied by site. At two sites, screening questionnaires were provided immediately to all adults on attendance. At the third site, all adult attendees were identified from an electronic database and were asked to complete the screening questionnaire during a telephone interview before their visit. The sampling period was extended to include May-November 2007 to attain the necessary sample size.

The screening questionnaire ascertained age, sex, smoking history and any self-reported previous respiratory diagnosis. Patients aged 40 years or more with a smoking history of at least 20 pack-years were invited to attend an assessment session within four weeks after completing the questionnaire. They were not requested to stop using any current respiratory medications.

\section{Assessment session}

After providing informed consent, participants completed a face-to-face interview regarding limitations resulting from dyspnea (according to the Medical Research Council dyspnea scale $^{12}$ ) and the presence of respiratory symptoms (Appendix 1, available at www.cmaj.ca/cgi/content/full/cmaj.091784 /DC1). An experienced technologist performed portable spirometry. Those with spirometric evidence of COPD ${ }^{13,14}$ were requested to complete a second face-to-face interview regarding home oxygen use and comorbid health conditions (Appendix 1). Spirometry was delayed for a minimum of four weeks following resolution of any reported respiratory infection. It was not performed if a participant met specific criteria thought to compromise his or her safety. ${ }^{3}$

\section{Spirometry}

Spirometry was performed according to international guidelines ${ }^{15}$ using a calibrated digital hand-held spirometer. All participants who had a ratio of forced expiratory volume in the first second of expiration $\left(\mathrm{FEV}_{1}\right)$ to forced vital capacity (FVC) of less than 0.7 and an $\mathrm{FEV}_{1}$ of less than $80 \%$ predicted underwent postbronchodilator spirometry 20 minutes following two puffs of salbutamol $(200 \mu \mathrm{g})$. We defined COPD as a postbronchodilator $\mathrm{FEV}_{1} / \mathrm{FVC}$ ratio of less than 0.7 and $\mathrm{FEV}_{1}$ of less than $80 \%$ predicted (GOLD stage 2 or higher). ${ }^{13,14,16}$ Predicted values for $\mathrm{FEV}_{1}$ were calculated using the equations of Hankinson and colleagues. ${ }^{17}$

We used quality-assurance procedures based on those used in a recent large international study of COPD: $:^{18}$ use of the same model of spirometer at all data-collection sites; standardized training of all staff responsible for data collection; collection and review of pilot data on five clinic attendees at each site; and a minimum of two visits by the study coordinator to each site. ${ }^{19}$

For immediate use in the study, spirometry had to yield three acceptable tracings, with the two best FVC values and the two best $\mathrm{FEV}_{1}$ values within $150 \mathrm{~mL}$ of each other. ${ }^{15}$ Tests that yielded only one acceptable tracing, or two acceptable tracings in which the measurements were not within $150 \mathrm{~mL}$ of each other, were reviewed by the study coordinator, senior pulmonary function technologist and an

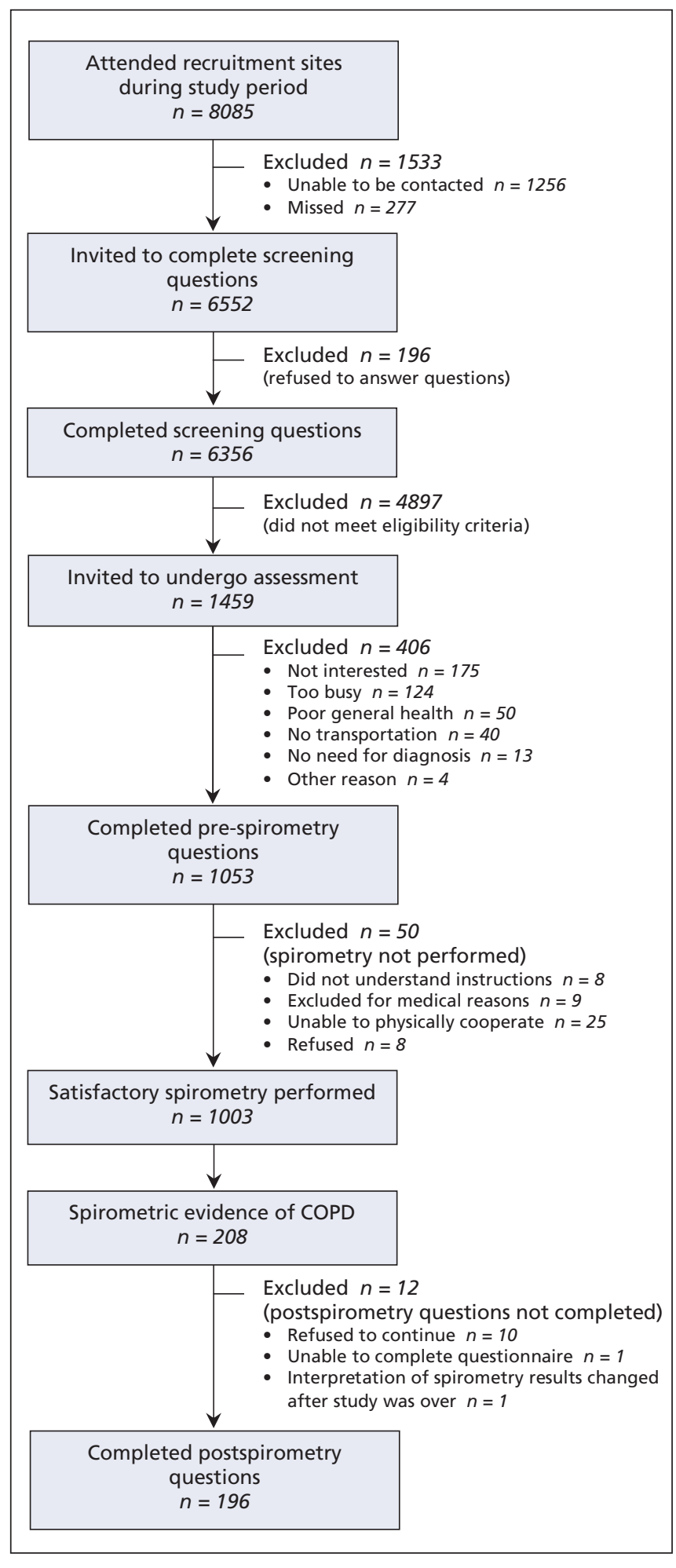

Figure 1: Recruitment and flow of participants. 
experienced respirologist. If there was any uncertainty regarding whether the results met the criteria for a diagnosis of COPD, spirometry was repeated following advice to the site technologist regarding how to optimize the quality of the tracings.

\section{Chart abstraction}

To identify clinical characteristics that could be used by family physicians to assist in distinguishing patients with and without COPD, the charts of participants who had spirometric evidence of COPD during the initial 12-month recruitment period were reviewed and data extracted on any diagnosis of COPD and the number of visits to a primary care physician because of a respiratory problem. Each participant with COPD was matched for sex, age (within five years) and recruitment site with three participants (or fewer, if three suitable matches could not be identified) who did not meet the spirometric criteria. Participants were then classified into four groups: correctly diagnosed COPD (spirometry results positive, chart positive); undiagnosed COPD (spirometry tests positive, chart negative); overdiagnosed COPD (spirometry results negative, chart positive); and no COPD (spirometry results negative, chart negative).

\section{Data management and analysis}

Data were faxed from the participating sites to the central data-management facility at McMaster University. This facility reported inconsistencies, discrepancies or missing data to the study site every two weeks. Required corrections were made within five business days. Prospective power calculations indicated that a sample size of 1000 patients would obtain a sufficiently narrow $95 \%$ confidence interval (CI) around the proportion of participants with COPD.

\section{Statistical analysis}

The prevalence of COPD was estimated as the number of participants who met the spirometric criteria for the disease, expressed as a proportion of those for whom valid spirometric measurements were available.

We performed logistic regression analysis using age, sex, current smoking status, number of respiratory symptoms (reported during the assessment session) and number of visits to a primary care physician because of a respiratory problem (collected through chart review) as independent variables. The dependent variable was accuracy of COPD diagnosis, dichotomized in separate analyses as: undiagnosed versus no COPD; correctly diagnosed versus overdiagnosed COPD; or undiagnosed versus correctly diagnosed COPD. We considered a $p$ value of 0.05 or less to be significant.

\section{Results}

During the study period, 8085 patients attended the three recruitment sites. A total of 6552 were approached to complete the screening questionnaire, of whom 6356 (97.0\%) agreed to answer the questions. Of the 1459 patients who met the eligibility criteria, 406 (27.8\%) declined participation and $50(3.4 \%)$ were unable to undergo spirometry (Figure 1). Compared with the 1053 participants, nonparticipants were more likely to be female $(54.2 \%$ v. $48.2 \% ; p=0.047)$ and current smokers $(53.2 \%$ v. $43.3 \% ; p<0.001)$. Of the 1003 participants for whom valid spirometric data were available, $613(61.1 \%), 337(33.6 \%)$ and $53(5.3 \%)$ were recruited from the suburban, rural and urban sites, respectively.

Of the 1003 participants who completed spirometry, 208 met the spirometric criteria for COPD, for a prevalence of $20.7 \%$ (95\% CI $18.3 \%$ to $23.4 \%$ ). The characteristics of the partici-

Table 1: Characteristics of 1003 participants aged 40 years and ol der for whom results of spirometry were available

Result of spirometry

\begin{tabular}{|c|c|c|c|}
\hline \multirow[b]{2}{*}{ Characteristic } & \multicolumn{3}{|c|}{ Result of spirometry } \\
\hline & $\begin{array}{l}\text { No COPD } \\
n=795\end{array}$ & $\begin{array}{c}\text { GOLD stage } 2 \text { COPD* } \\
n=164\end{array}$ & $\begin{array}{c}\text { GOLD stage } 3 \text { or } 4 \text { COPD }+ \\
n=44\end{array}$ \\
\hline Age, yr, mean (SD) & $59.1(10.5)$ & $64.0(9.9)$ & $68.0(8.7)$ \\
\hline Sex, male:female ratio & 418:377 & $80: 84$ & $23: 21$ \\
\hline Current smoker, no. (\%) & $337(42.4)$ & $72(43.9)$ & $24(54.5)$ \\
\hline $\mathrm{FEV}_{1} / \mathrm{FVC}$ ratio, mean (SD) & $0.74(0.07)$ & $0.59(0.07)$ & $0.42(0.10)$ \\
\hline $\mathrm{FEV}_{1}, \%$ predicted, mean (SD) & $89.0(13.2)$ & $67.8(7.7)$ & $38.1(7.7)$ \\
\hline Smoking history, pack-years, mean (SD) & $33.0(14.0)$ & $38.3(16.4)$ & $46.8(23.4)$ \\
\hline Body mass index, mean (SD) & $29.7(6.4)$ & $27.9(5.7)$ & $25.0(5.5)$ \\
\hline White, no. (\%) & $791(99.5)$ & $163(99.4)$ & $43(97.7)$ \\
\hline $\begin{array}{l}\text { Medical Research Council dyspnea score, } \\
\text { median (IQR) }\end{array}$ & $1(1-2)$ & $2(1-2)$ & $2(2-3)$ \\
\hline Self-reported diagnosis of COPD, no. (\%) & $43(5.6) \ddagger$ & $43(26.7) \S$ & $24(54.5)$ \\
\hline$\geq 1$ respiratory symptom, no. (\%) & $519(65.6)$ ** & $121(74.7) \dagger \dagger$ & $39(90.7) \ddagger \ddagger$ \\
\hline
\end{tabular}

Note: $\mathrm{COPD}=$ chronic obstructive pulmonary disease, $\mathrm{FEV}_{1}=$ forced expiratory volume in first second of expiration, $\mathrm{FVC}=$ forced vital capacity, IQR = interquartile range, $\mathrm{SD}=$ standard deviation.

${ }^{*} \mathrm{FEV}_{1} / \mathrm{FVC}<0.7$ and $\mathrm{FEV}_{1} \geq 50 \%$ predicted but $<80 \%$ predicted.

TFEV $/$ /FVC $<0.7$ and $\mathrm{FEV}_{1}<50 \%$ predicted.

‡Data available for 774. §Data available for 161. **Data available for 791. ††Data available for 162. ¥‡Data available for 43. 
pants who completed spirometry are summarized in Table 1. Of the 196 participants with COPD who completed the interview after spirometry, $58(29.6 \%)$ reported a previous diagnosis of heart disease, $100(51.0 \%)$ hypertension, 43 (21.9\%) diabetes, $12(6.1 \%)$ stroke, $3(1.5 \%)$ lung cancer and $3(1.5 \%)$ tuberculosis. Four $(2.0 \%)$ of the 196 participants were using home oxygen. Of the 205 participants with positive spirometry results who completed the interview about respiratory symptoms before spirometry, 67 (32.7\%) reported having received a prior diagnosis of COPD. Cough was the most common respiratory symptom, reported by 110 individuals $(53.7 \%)$.

Table 2 presents the characteristics of the $382(38.1 \%)$ participants for whom chart abstraction was undertaken, including 107 (93.9\%) of 114 who had positive spirometry results and 275 matched controls. Table 3 presents the results of the logistic regression analysis of the association between patient characteristics and the accuracy of the COPD diagnosis. The median time between spirometry and the most recent visit to a primary care practitioner was 1.1 (interquartile range $0.4-2.9$ ) years. Compared with patients whose COPD was undiagnosed $(n=49)$, those correctly found not to have COPD $(n=$ 230) were similar in terms of age $(p=0.44)$, sex $(p=0.78)$, current smoking status $(p=0.77)$, number of respiratory symptoms $(p=0.70)$ and number of visits to a primary care physician because of a respiratory problem $(p=0.10)$.

Compared with patients whose COPD was correctly diagnosed $(n=58)$, those in whom COPD was overdiagnosed $(n=45)$ described fewer respiratory symptoms $(p=0.045)$ but otherwise were similar in terms of age $(p=0.99)$, sex $(p=$ $0.25)$, current smoking status $(p=0.56)$ and number of visits to a primary care physician because of a respiratory problem $(p=$ 0.37). The same was true when we compared patients whose COPD was correctly diagnosed and those with undiagnosed COPD, with the latter describing fewer respiratory symptoms $(p=0.002)$ but otherwise being similar in terms of age $(p=$ $0.23)$, sex $(p=0.70)$, current smoking status $(p=0.08)$ and number of visits because of a respiratory problem $(p=0.44)$.

\section{Interpretation}

We identified COPD in approximately one of every five adults who visited a primary care practitioner for any reason, were 40 years or older and had a smoking history of at least 20 pack-years. Although more than three-quarters of the patients with COPD reported at least one respiratory symptom, two-thirds were unaware of their diagnosis. These findings suggest that adults who attend a primary care practice with known risk factors for COPD are important targets for screening and early intervention.

The prevalence of COPD in our cohort was considerably higher than the $10.1 \%$ reported in the Burden of Obstructive Lung Disease (BOLD) study that recruited participants of similar age and used identical diagnostic criteria. ${ }^{3}$ However, unlike previous studies that used population-based sampling, ${ }^{3,18}$ we recruited only patients with a smoking history of at least 20 pack-years who had visited a primary care practitioner. In the BOLD study, the prevalence of COPD in the subgroup of heavy smokers was $15.5 \%-33.9 \%$ among men and $2.7 \%-29.7 \%$ among women across various countries. ${ }^{3}$ Our estimate of COPD prevalence in a sample of more than 1000 individuals is more precise $(20.7 \%$, 95\% CI $18.3 \%-$ 23.4\%) and agrees with earlier reports of a high prevalence of COPD among people with known risk factors. ${ }^{46}$

Although underdiagnosis of COPD has been previously reported ${ }^{20}$ the extent of it in our cohort is especially striking given that all of the patients had two important risk factors for COPD. ${ }^{3}$ Moreover, almost $50 \%$ of the patients with COPD were still smoking and therefore at increased risk for progression to more severe disease. Early diagnosis in this group is particularly important because spirometric evidence of airflow obstruction may help health care professionals to optimize smoking cessation. ${ }^{21,22}$

Differences in respiratory symptoms between the patients with correctly diagnosed COPD and those with overdiagnosed disease were modest and did not reflect differences in age, sex,

Table 2: Characteristics of 382 participants for whom chart abstraction was undertaken

\begin{tabular}{lcccc}
\hline Characteristic & $\begin{array}{c}\text { COPD correctly } \\
\text { diagnosed* } \\
n=58\end{array}$ & $\begin{array}{c}\text { COPD } \\
\text { undiagnosedt } \\
n=49\end{array}$ & $\begin{array}{c}\text { COPD } \\
\text { overdiagnosed } \neq \\
n=45\end{array}$ & $\begin{array}{c}\text { No COPD } \\
n=230\end{array}$ \\
\hline Age, yr, mean (SD) & $64.2(8.2)$ & $65.0(10.3)$ & $65.5(9.3)$ & $62.6(8.6)$ \\
\hline Sex, male:female ratio & $26: 32$ & $26: 23$ & $25: 20$ & $118: 112$ \\
\hline Current smoker & $31(53.4)$ & $14(28.6)$ & $23(51.1)$ & $62(27.0)$ \\
$\geq 2$ respiratory symptoms & $43(74.1)$ & $19(38.8)$ & $22(50.0) \dagger \dagger$ & $84(36.5)$ \\
$\begin{array}{l}\text { No. of visits to a primary care physician because } \\
\text { of respiratory problem, rate per patient-year** }\end{array}$ & 0.92 & 0.45 & 0.74 & 0.32 \\
$\begin{array}{l}\text { Underwent previous spirometry** } \\
\text { Had been prescribed any respiratory medication** }\end{array}$ & $51(87.9)$ & $19(38.8)$ & $30(66.7)$ & $63(27.4)$ \\
\hline
\end{tabular}

Note: COPD = chronic obstructive pulmonary disease, SD = standard deviation.

*Positive spirometry result, diagnosis of COPD in chart.

tPositive spirometry result, no diagnosis of COPD in chart.

$¥$ Negative spirometry result, diagnosis of COPD in chart.

$\S$ Negative spirometry result, no diagnosis of COPD in chart.

**Data extracted from charts.

t†Data available for $n=44$. 
smoking status or visits to a primary care physician. Nor did the clinical characteristics differ between the patients with undiagnosed COPD and those without the disease, although the former group reported fewer respiratory symptoms than those with correctly diagnosed COPD. The absence of distinguishing clinical characteristics within the population tested should encourage the use of spirometry in patients with known risk factors for COPD who visit a primary care practitioner for any reason.

Our selective recruitment of patients with known risk factors for COPD who had visited a primary care practitioner for any reason allowed us to find novel evidence that this population has a high prevalence of COPD. In addition, prior diagnosis of COPD was based on their family doctor's diagnosis, validated by chart extraction, rather than based on self-report as in most studies.

\section{Limitations}

Our diagnostic criteria for COPD, based on the $\mathrm{FEV}_{1} / \mathrm{FVC}$ ratio and $\mathrm{FEV}_{1}$ percent predicted, can be questioned, particularly among elderly patients, in whom the $\mathrm{FEV}_{1} / \mathrm{FVC}$ ratio may be normally reduced as a function of aging..$^{23-25}$ However, our classification, which represents those with stage 2 COPD or higher according to the GOLD classification, ${ }^{16}$ is consistent with the definitions of COPD provided by international guidelines ${ }^{10,13,26}$ and is the definition used in the BOLD study. ${ }^{3}$ This classification is supported by epidemiologic data ${ }^{27}$ and allows grouping of people according to the severity of disease, which is linked to outcomes such as death, hospital admission and comorbid conditions. ${ }^{28-30}$ By not including GOLD stage 1 COPD, or mild COPD according to Canadian guidelines, ${ }^{10}$ we minimized the likelihood of including people with asthma and provided a more conservative estimate than in some studies..$^{18,31,32}$ Furthermore, by excluding people with GOLD stage 1 disease, we optimized the likelihood of identifying individuals with disease-specific impairment in health status. ${ }^{33}$

Although we selected rural, suburban and urban populations, our sample was almost exclusively white, which limits the generalizability of our findings to other ethnic groups. There was some disparity in prevalence estimates among the recruitment sites; however, we did not include a detailed assessment of variables that might account for these differences, such as literacy, socio-economic status and occupational exposures. The small proportion of participants from the urban site was most likely due to the very high proportion of international immigrants in this region and their reluctance to participate in a study regarding lung health.

Our rates of participation are concordant with those reported in previous studies., ${ }^{3,18}$ Participants and nonparticipants differed in some characteristics in a manner which, if nonresponse bias was introduced, might have led to under- estimation of COPD prevalence. Although the measurement properties of the questions about the presence of respiratory symptoms have not been investigated, they are basic questions commonly used in clinical practice to screen for cases of COPD.

\section{Conclusions}

Our findings show that early detection of COPD in high-risk patients in a primary care setting is feasible. For health policy-makers, this should provide a stimulus for the development of preventive care programs designed for COPD patients in family practice. Success of early intervention in this population could result in important reductions in mortality, morbidity and health care expenditures related to COPD, although this remains to be demonstrated in future evaluations. For practitioners, our results call for a higher index of suspicion for the presence of COPD in patients aged 40 years or older with a substantial smoking history, as well as a wider use of spirometry for diagnosis. Further research is indicated to define more clearly the reasons for underdiagnosis and overdiagnosis of COPD in primary care settings.

\section{This article has been peer reviewed.}

Competing interests: Richard Hodder has attended advisory board meetings and provided continuing medical education for which he has received honoraria from various pharmaceutical companies, including AstraZeneca, Boehringer-Ingelheim, GlaxoSmithKline, Novartis, Nycomed, Merck Frosst and Pfizer. Matthew Stanbrook is a member of the executive of the Ontario Thoracic Society. No competing interests declared by Kylie Hill, Roger Goldstein, Gordon Guyatt, Maria Blouin, Wan Tan, Lori Davis, Diane HeelsAnsdell, Marko Erak, Pauline Bragaglia or Itamar Tamari.

Disclaimer: Matthew Stanbrook is a coauthor of this article. As a deputy editor of $C M A J$, he was not involved in the selection of peer reviewers or the vetting of the manuscript before its acceptance.

Contributors: Kylie Hill contributed to the interpretation of the study results and drafted the article. Roger Goldstein, Gordon Guyatt and Wan Tan contributed to the study design and interpretation of the results. Maria Blouin, Lori Davis, Marko Erak, Pauline Bragaglia and Itamar Tamari contributed to the study design and acquisition of data. Diane Heels-Ansdell performed the 
data analyses and contributed to the interpretation of the results. Richard Hodder contributed to the study design. Matthew Stanbrook contributed to the study design and interpretation of the results. All of the authors revised the manuscript critically for important intellectual content and approved the final version submitted for publication.

Acknowledgements: The authors thank the following people for their assistance with this project: Peggy Austin, Teresa To, Karen Jones, Christina Dolgowicz, Anjie Valgardson, Janice Belanger, Jennifer Zufelt, Josh McColman, Nancy Juby, Deana Juby and Nataliya Vasylevych.

Funding: Funding for this study was provided by the Government of Ontario and the Ontario Lung Association.

\section{REFERENCES}

1. Murray CJ, Lopez AD. Alternative projections of mortality and disability by cause 1990-2020: Global Burden of Disease Study. Lancet 1997;349:1498-503.

2. Chapman KR, Mannino DM, Soriano JB, et al. Epidemiology and costs of chronic obstructive pulmonary disease. Eur Respir J 2006;27:188-207.

3. Buist AS, McBurnie MA, Vollmer WM, et al. International variation in the prevalence of COPD (the BOLD Study): a population-based prevalence study. Lance 2007;370:741-50

4. Zielinski J, Bednarek M. Early detection of COPD in a high-risk population using spirometric screening. Chest 2001;119:731-6.

5. Bednarek M, Gorecka D, Wielgomas J, et al. Smokers with airway obstruction are more likely to quit smoking. Thorax 2006;61:869-73.

6. Maleki-Yazdi MR, Lewczuk CK, Haddon JM, et al. Early detection and impaired quality of life in COPD GOLD stage 0: a pilot study. COPD 2007;4:313-20.

7. Fletcher C, Peto R. The natural history of chronic airflow obstruction. BMJ 1977; 1 1645-8.

8. Dales RE, Vandemheen KL, Clinch J, et al. Spirometry in the primary care setting: influence on clinical diagnosis and management of airflow obstruction. Chest 2005;128:2443-7.

9. Walker PP, Mitchell P, Diamantea F, et al. Effect of primary-care spirometry on the diagnosis and management of COPD. Eur Respir J 2006;28:945-52.

10. O'Donnell DE, Aaron S, Bourbeau J, et al. Canadian Thoracic Society recommendations for management of chronic obstructive pulmonary disease - 2007 update. Can Respir J 2007;14 Suppl B:5B-32B

11. Bourbeau J, van der Palen J. Promoting effective self-management programmes to improve COPD. Eur Respir J 2009;33:461-3.

12. Bestall JC, Paul EA, Garrod R., et al. Usefulness of the Medical Research Council (MRC) dyspnoea scale as a measure of disability in patients with chronic obstructive pulmonary disease. Thorax 1999;54:581-6.

13. BTS guidelines for the management of chronic obstructive pulmonary disease. The COPD Guidelines Group of the Standards of Care Committee of the BTS. Thorax 1995;(Suppl 5):S1-28.

14. National Collaborating Centre for Chronic Conditions. Chronic obstructive pulmonary disease. National clinical guideline on management of chronic obstructive pulmonary disease in adults in primary and secondary care. Thorax 2004;59(Suppl 1):1-232.

15. Miller MR, Hankinson J, Brusasco V, et al. Standardisation of spirometry. Eur Respir J 2005;26:319-38.

16. Rabe KF, Hurd S, Anzueto A, et al. Global strategy for the diagnosis, management, and prevention of chronic obstructive pulmonary disease: GOLD executive summary. Am J Respir Crit Care Med 2007;176:532-55.

17. Hankinson JL, Odencrantz JR, Fedan KB. Spirometric reference values from a sample of the general US population. Am J Respir Crit Care Med 1999;159:179-87.

18. Menezes AM, Perez-Padilla R, Jardim JR, et al. Chronic obstructive pulmonary disease in five Latin American cities (the PLATINO study): a prevalence study. Lancet 2005;366:1875-81

19. Perez-Padilla R, Vazquez-Garcia JC, Marquez MN, et al. Spirometry qualitycontrol strategies in a multinational study of the prevalence of chronic obstructive pulmonary disease. Respir Care 2008;53:1019-26.

20. Mannino DM, Gagnon RC, Petty TL, et al. Obstructive lung disease and low lung function in adults in the Unites States: data from the National Health and Nutrition Examination Survey, 1988-1994. Arch Intern Med 2000;160:1683-9.

21. Stratelis G, Molstad S, Jakobsson P, et al. The impact of repeated spirometry and smoking cessation advice on smokers with mild COPD. Scand J Prim Health Care 2006;24:133-9.

22. Parkes G, Greenhalgh T, Griffin M, et al. Effect on smoking quit rates of telling patients their lung age: the Step2quit randomised controlled trial. BMJ 2008;336: 598-600.

23. Roberts SD, Farber MO, Knox KS, et al. FEV $/$ FVC ratio of $70 \%$ misclassifies patients with obstruction at the extremes of age. Chest 2006;130:200-6.

24. Schermer TR, Smeele IJ, Thoonen BP, et al. Current clinical guideline definitions of airflow obstructive and COPD overdiagnosis in primary care. Eur Respir $J$ 2008;32:945-52.
25. Swanney MP, Ruppel G, Enright PL, et al. Using the lower limit of normal for the $\mathrm{FEV}_{1} / \mathrm{FVC}$ ratio reduces misclassification of airway obstruction. Thorax 2008;63: 1046-51.

26. McKenzie DK, Abramson M, Crockett AJ, et al. The COPD-X plan: Australia and New Zealand guidelines for the management of chronic obstructive pulmonary disease 2009. Bowen Hills (Australia): The Australian Lung Foundation; 2009. Available: www.copdx.org.au/guidelines/index.asp (accessed June 2009).

27. Johannessen A, Lehmann S, Omenass ER, et al. Post-bronchodilator spirometry reference values in adults and implications for disease management. Am J Respir Crit Care Med 2006;173:1316-25.

28. Mannino DM, Doherty DE, Buist AS. Global Initiative on Obstructive Lung Disease (GOLD) classification of lung disease and mortality: findings from the Atherosclerosis Risk in Communities (ARIC) study. Respir Med 2006;100:115-22.

29. Mannino DM, Thorn D, Swensen A, et al. Prevalence and outcomes of diabetes, hypertension and cardiovascular disease in COPD. Eur Respir J 2008;32:962-9.

30. Mannino DM, Davis KJ, Kiri VA. Chronic obstructive pulmonary disease and hospitalizations for pneumonia in a US cohort. Respir Med 2009;103:224-9.

31. Shahab L, Jarvis MJ, Britton J, et al. Prevalence, diagnosis and relation to tobacco dependence of chronic obstructive pulmonary disease in a nationally representative population sample. Thorax 2006;61:1043-7.

32. Zhong N, Wang C, Yao W, et al. Prevalence of chronic obstructive pulmonary disease in China: a large, population-based survey. Am J Respir Crit Care Med 2007; 176:753-60.

33. Antonelli-Incalzi R, Imperiale C, Bellia V, et al. Do GOLD stages of COPD severity really correspond to difference in health status? Eur Respir J 2003;22:444-9.

Correspondence to: Dr. Roger S. Goldstein, West Park Healthcare Centre, 82 Buttonwood Ave., Toronto ON M6M 2J5;

rgoldstein@westpark.org

\section{CMAJ celebrates}

\section{0 years \\ in 2011!}

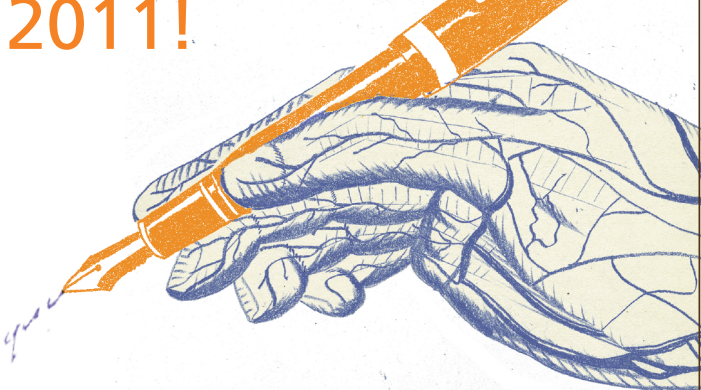

Visit www.cmaj.ca

We want to hear from you. Tell us how CMAJ affected your practice or your life, recollect coincidences, controversies or quirky content...

Send to 100years@cmaj.ca or Carole Corkery, CMAJ, 1867 Alta Vista Dr., Ottawa ON K1G 5W8 